\title{
The Common Warehouse Model and Profit Distribution of the Express Industry
}

\author{
Li Wang * ${ }^{\mathbb{C}}$, Xi Wang $(\mathbb{D}$ and Xilong Cai \\ School of Modern Post, Beijing University of Posts and Telecommunications, Beijing 100876, China; \\ daytoy_wangxi@163.com (X.W.); 2508418876@bupt.edu.cn (X.C.) \\ * Correspondence: wang_li@bupt.edu.cn
}

\begin{abstract}
The sharing mode of the logistics industry can effectively solve the new problems arising from the rapid development of the express industry. However, only when the interests are reasonably distributed can the sharing mode be implemented for a long time. This paper discusses the connotation of unified warehouse and distribution, designs the operation mode of a unified warehouse and distribution, and solves the profit distribution problem of a unified warehouse and distribution alliance based on the improved Shapley value method. Firstly, the traditional Shapley value method is improved by using a comprehensive correction factor, including the proportions of investment, risk, and innovative research contributions. Secondly, each factor's weight is determined by the analytic hierarchy process (AHP), and the profits are distributed according to the contribution of each express enterprise to the alliance. Finally, an example is given to verify the validity of the modified algorithm. It proves that the modified Shapley value method can effectively solve the problem of profit distribution.
\end{abstract}

Keywords: improved Shapley value method; correction factor; unified warehouse and distribution; shared logistics model

check for

updates

Citation: Wang, L.; Wang, X.; Cai, X. The Common Warehouse Model and Profit Distribution of the Express Industry. Algorithms 2021, 14, 50. https://doi.org/10.3390/a14020050

Academic Editor: Maciej Drozdowski Received: 29 December 2020 Accepted: 28 January 2021

Published: 4 February 2021

Publisher's Note: MDPI stays neutral with regard to jurisdictional clai$\mathrm{ms}$ in published maps and institutional affiliations.

Copyright: (C) 2021 by the authors. Licensee MDPI, Basel, Switzerland. This article is an open access article distributed under the terms and conditions of the Creative Commons Attribution (CC BY) license (https:// creativecommons.org/licenses/by/ $4.0 /)$.

\section{Introduction}

In recent years, the booming of e-commerce has led to the rapid development of the express industry and gave birth to new problems. In 2019, the business of express delivery exceeded 60 billion pieces, contributing over $50 \%$ to the growth of the world's express industry. However, at the same time, problems such as "out of stock during holidays" and "slow express" have been exposed successively, which have not only affected customer experience but also reduced efficiency and kept costs high, hindering the healthy and rapid development of the express industry. The outbreak of the problem is related to the lack of effective cooperation in China's express industry. At present, each express delivery enterprise in China operates in its own way. Limited by the ability and resources of each express enterprise, each express enterprise plans its sorting center, distribution network, and distribution route. The distribution network is unreasonable, and the distribution route is not scientific. Besides, transportation means and express-related materials are not shared among express enterprises, which leads to the lack of efficiency of the industry as a whole. When there are idle resources, the industry cannot meet the demand for express during peak periods, thereby causing a waste of resources. With the rapid increase of express delivery volume in China, the demand for resources in the express industry increases accordingly. If resources are still not fully utilized efficiently, the difficulty of meeting the demands will become more and more prominent. Therefore, "sharing," as a means to optimize scattered and idle resources, is of great significance to solve the above problems.

Throughout the whole field of logistics, scholars from all over the world put forward the sharing model to realize the industry's transformation. From the cloud warehouse's resources sharing mode concentrating on storage aspects and the unit (pallet, turnover box, etc.) in cyclic sharing mode, to common distribution and shared logistics mode focused 
on the distribution and logistics crowdsourcing sharing mode, "sharing" broke the space and time limits of resources, and realized the integrated use of idle and scattered resources, thereby effectively reducing the costs of enterprise management. However, the express delivery industry in China has not formed a real scale sharing system in recent years, and some existing sharing logistics modes only achieve the common express cabinets and public outlets at the end, and each express delivery enterprise still operates independently in transportation, storage, distribution, and other operations. There are two main reasons. On the one hand, the express delivery industry is restricted by these problems:

- $\quad$ Research of sharing in the field of logistics and express delivery started late, with little experience and much copying;

- $\quad$ Size and distribution proposals for warehouses are unreasonable;

- The degree of digital intelligence for distribution and storage areas is low;

- $\quad$ There are not enough effective coordination mechanisms.

On the other hand, the industry lacks an effective incentive to promote cooperation and resource sharing between enterprises. Thus when discussing the unified warehouse and distribution, it is necessary to specifically discuss a fair and effective allocation method, in order to effectively guarantee the express companies gain greater profits from "sharing" promoting the express delivery enterprises to actively participate in the sharing. Besides, it is worth noting that resource sharing is inseparable from the angle of profit distribution. Scholars adopted the Shapley value method, Raiffa method, Nash negotiation solution, and other sharing enterprises to make reasonable profit distributions to ensure the fair and stable operation of the model.

This paper uses the existing shared logistics model for reference and combines it with the operational characteristics of the express industry to amend the Shapley value method to solve the profit distribution problem of the express enterprise alliance under this model.

\section{Literature Review}

\subsection{Logistics Sharing Mode}

Logistics includes transportation, storage, handling, loading, unloading, information management, etc. The existing sharing logistics mode often discusses one of those links. Scholars' research on the shared logistics model is mainly carried out on five aspects: social and economic profits brought by the shared logistics model, the innovation of shared logistics model, the location problem of shared logistics, cost minimization (benefit maximization) problem, and the profit distribution problem.

The research on the social and economic profits of the shared logistics model, namely, the research and understanding of the positive significance of the shared logistics model, mainly verifies the enterprise profits and social profits of the shared logistics model in environmental protection, cost reduction, service quality improvement, and other aspects. As for location problem of the distribution center, scholars at home and abroad concentrate on the study of the impacts of the distribution center and location method, adopting the method of combining quantitative or qualitative or both, often through the establishment of the mathematical model, using the queuing theory, nonlinear programming method, the heuristic algorithm, the fuzzy clustering method, and the mixed integer programming method to solve the problem, in order to determine the reasonable location of a distribution center [1]. Most of the research on cost minimization focuses on the warehouse. Among them, Sarkar and Saren [2] used different demand patterns to check the optimum profits for different situations for the inventory in the article, in order to maximize average profit per unit time for retailer. Shin et al. [3] added the service level limitation into the model so that the out-of-stock costs were avoided. Kumar et al. [4] considered the cost minimization of the double warehouse system with demand and time varying. In this part, scholars tried to control the cost from many different aspects, including but not limited to supply and demand, time in and out of the warehouse, service level, and management standard, so as to scientifically reduce the cost of a warehouse from multiple perspectives. 
As for innovation of the mode, scholars focused on the different practical problems, from each link of logistics put forward many types of sharing logistics mode, from different shared objects took a different way of sharing, and formed a variety of operating modes. With the collaborative principle, Li et al. [5] built the sharing storehouse with three sharing mechanisms: formation mechanism, the implementation mechanism, and the guarantee mechanism, based on a study of the content and motivations in a shared warehouse. On this basis, they put forward the basis of development of the shared warehouse and analyzed the implementation of a unified warehouse and distribution. Yang et al. [6] mainly focused on the design of the joint distribution mode under the background of "Internet +"; and discussed how to solve "the last kilometer" and "the last one hundred meters" problems through the joint distribution mode innovation. They put forward the electronic commerce and express logistics distribution mode, and the express end joint distribution service mode in a limited urban area, and proposed perfecting the urban express joint distribution system at the end through building a cloud platform, and establishing a large data analysis system and $\mathrm{O} 2 \mathrm{O}$ e-commerce system. Such innovations combined new technologies and took into account new practical problems, which had great positive impacts on the development and implementation of the model. Li [7] analyzed mutual urban community logistics service mode from four aspects, the organization mechanism, the cooperation mechanism, information sharing, and the collaborative decision-making mechanism, and mentioned that only by forming a complete operating mechanism could people achieve the goal of common good. The organizational mechanism is the prerequisite. The cooperation mechanism is the power source. The sharing mechanism is the necessary support information. The collaborative decision-making mechanism is the basic guarantee. The design of the system was more comprehensive, but the construction of a complete system was difficult and not easy to achieve. $\mathrm{Wu}$ [8] built a new joint distribution alliance model of electrical business logistics ends and put forward the concrete implementation strategy. That is, Wu did so by joint investment and receipt, establishing a shared information platform, improving the express formula, making a cost allocation mechanism, forming a reasonable cooperation organization mode to achieve effective operation of the model involving a storage center, making a joint distribution center, and coordinating a distribution network. Shi [9] and Li $[10,11]$ studied the joint distribution method of America and Japan. Ge [12] analyzed the categories of joint distribution patterns, such as one-to-many and manyto-many. One-to-many mode is an orderly delivery activity conducted by a distribution enterprise for multiple customers according to the distribution needs and routes, and the targeted users (users involved in the "last kilometer problem" such as individual users and users with high frequency, large quantities, and various categories such as supermarkets and drugstores). Many-to-many mode refers to the cooperation of multiple enterprises, overall arrangement of distribution, and joint service for multiple customers. This mode is mainly used in the joint distribution and transportation of long distance bulk goods by sea, air, and railway. The many-to-many model saves resources and costs because it can increase load rates and reduce redundant transportation by sharing space.

By comparing and analyzing the shared logistics model proposed by scholars, at present we summarize four shared logistics modes: cloud warehouse resource sharing mode, logistics equipment sharing mode, logistics crowdsourcing sharing model and the joint distribution and shared logistics model. Among them, logistics equipment sharing mode is limited to the sharing of things such as warehousing and freight equipment, with limited economic benefits and failure to form large-scale and systematic sharing, which limits the possibility of continuous evolution and innovation of this mode. Logistics crowd-sourcing mode focuses on the sharing of personnel in the distribution field, and is not closely related to the cooperation mode and profit among enterprises. Thus it is not considered in this paper. By combining the characteristics of the express industryscattered and irregular demand for express delivery and the demand for door-to-door delivery - this paper hopes to draw lessons from the cloud warehouse resource sharing mode and the shared distribution logistics mode of joint distribution in order to construct 
the shared distribution mode of the unified warehouse and distribution in the express industry. That is, to realize the "sharing" of storage and distribution. The operation process of the cloud warehouse is shown in Figure 1:

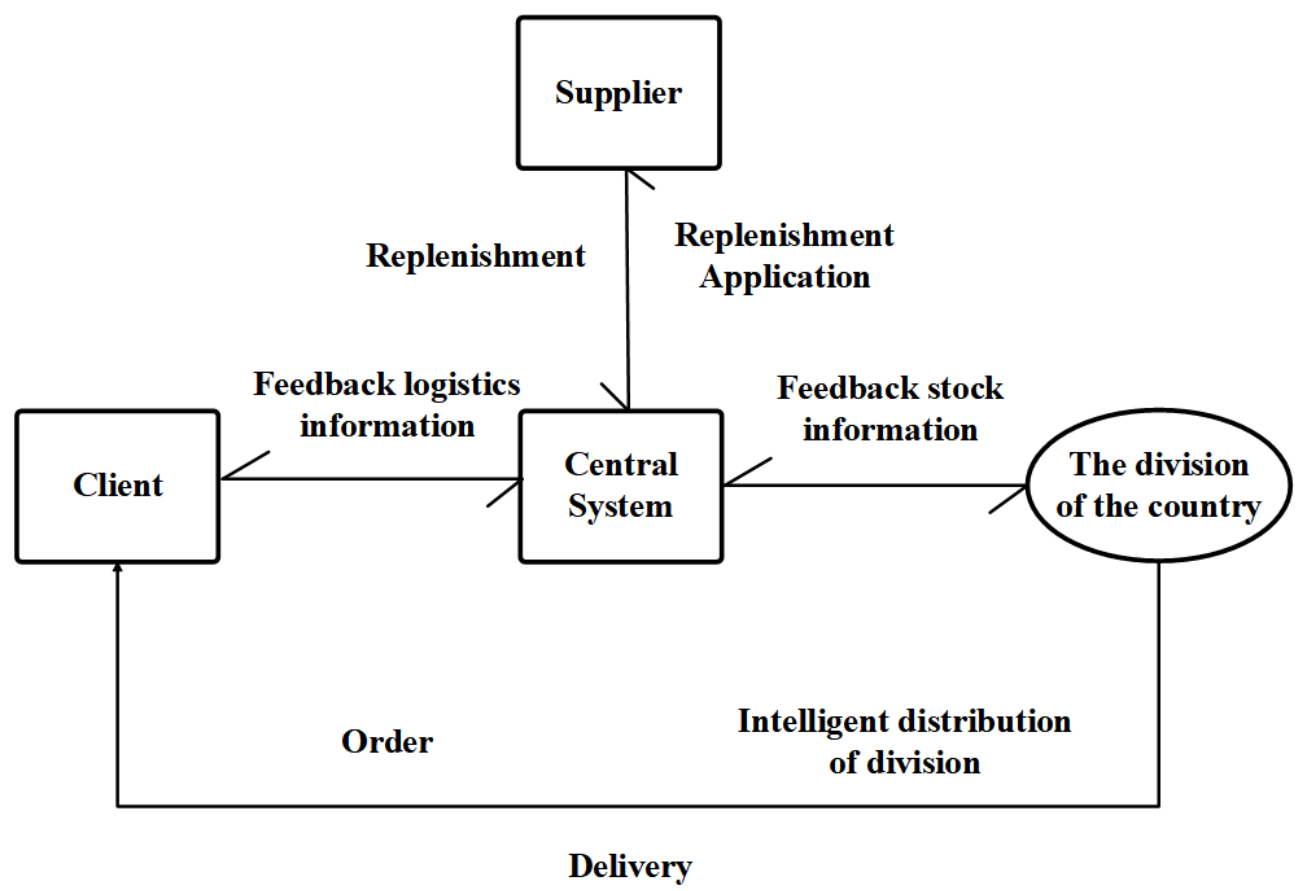

Figure 1. The operation flow of the cloud warehouse.

The core idea of cloud warehouse mode lies in the realization of a unified warehouse through sharing. That is, the effect of combining various scattered warehouses in the same logistics field to form a "warehouse network." In other words, express enterprises ally to integrate their existing warehouses through cooperation. Each warehouse is a node in the warehouse network with exchanges and sharing. The key to the joint distribution model lies in the means of "sharing," that is, the sharing of personnel, information, and resources. Such sharing in many aspects can make full use of the member enterprises' existing resources in the alliance to reduce costs and idle resources.

\subsection{The Problem of Profit Distribution}

At present, domestic and foreign scholars mainly apply game theory and multi-person cooperation theory to study profit distribution, and the research is mainly focused on distribution methods [13]. Zhao [14] set up the new distribution mode meeting profit demands of rural chain stores, third-party express enterprises, and joint distribution information platforms, and he put forward a distributing method of joint distribution's expected profits considering the business of the platform and the risk of express, in order to resolve conflict which exists between the three parties of interest. Shi [15] pointed out that when total effectiveness is uncertain, one can use the AHP method, the ANP method, and the fuzzy comprehensive evaluation method to estimate the possible utility values of different combinations of the union state, in order to get a more reasonable utility value under different alliance composite state, and obtain data needed for the Shapley value method, using Shapley value method on specific distribution calculations. Li [16] analyzed the influencing factors of the profit distribution of a retail chain's joint distribution alliance. She obtained the ranking of the importance of each influencing factor measure index, namely, benefit $>$ investment $>$ risk > contribution > cost. Then she used AHP and GEM methods to determine the weights of the influencing factors, and used the Raiffa method to distribute the interests of the small and large alliances according to how much each enterprise in the retail chain alliance brought benefits to the alliance. Zhang [17] built a 
profit distribution model between intelligent logistics park and resident enterprises based on dynamic Bayes, and discussed how the park or enterprises updated their understanding of each other's state based on dynamic Bayes, and determined their expected returns, so as to make decisions. The game reaches equilibrium when both parties find the optimal stable solution. Xu et al. [18] used the network analysis method to distribute the profits of the participants for the first time, and then adjusted the benefits of the first time according to the consumers' evaluation of the service level of each participant on the cloud logistics platform to achieve the incentive effect. Zhang [19] utilized the TOPSIS method to construct the profit distribution model.

It can be found from the existing literature that researchers not only tried a variety of methods (Shapley value method, Nash negotiation method, Raiffa solution, etc.) but also combined the algorithm with the practice respectively, while considering various realistic factors to improve the algorithm. However, the limitation lies in that scholars cannot comprehensively consider all influencing factors and often just directly give the reference values such as cost and risk as factors to improve the allocation method, without discussing these factors themselves and the possible relationships between them.

Among many methods, the Shapley value method distributing the profit for members of the alliance embodies the thought of sharing of profits based on contributions, so as to avoid making members of the group feel injustice has been done. Compared with other allocation means, the Shapley value method is more reasonable and fair, with more emphasis on the actual contributions to the interests of the whole alliance rather than the allocation methods which only refer to resource efficiency or the investments, or the combination of them. Besides, the Shapley value method reflects the process of a game for each member. In this way, each member of the alliance can be encouraged to make greater contributions to the alliance in order to share more profits, which is conducive to the overall benefit maximization and long-term development of the alliance. In other words, the Shapley value method has a considerable incentive and makes a good attempt at fairness.

\subsection{Using the Shapley Value Method to Solve the Problem of Profit Distribution}

The traditional Shapley value method must satisfy the following four axioms before the profit distribution: symmetry, validity, redundancy, and additivity. These four axioms are the premise for the Shapley value method to realize fair and reasonable allocation. On the basis of satisfying the above axioms, Shapley [20] gives the following allocation scheme:

$$
\begin{gathered}
\varphi_{i}(v)=\sum_{s \in S_{i}} \omega(|s|)[v(s)-v(s-\{i\})] \\
\omega(|s|)=\frac{(s-1) !(n-|s|) !}{n !}
\end{gathered}
$$

Among them, $\omega(|s|)$ is the weighted factor. $S_{i}$ is the set formed by all subsets containing members in $I .|s|$ is the number of elements in the set $s . v(s)-v(s-\{i\})$ indicates the contribution made by the member $i$ in the cooperative group. Such cooperation has a total of $(s-1) ! \cdot(n-|s|)$ ! occurrence modes, so the probability of occurrence of each kind is $\omega(|s|)$.

As the principle "distribution according to contribution" of the Shapley value method is more realistic, a large number of scholars choose to optimize the method of profit distribution and solve the problem of profit distribution by revising the Shapley value method. Cai and $\mathrm{Hu}$ [21] established the cooperative game model of self-lifting point alliance to integrate end-distribution resources, and distributed the benefits gained from joint distribution and joint self-lifting points among enterprises respectively through Shapley value method and Owen value method. Li [22] modified the Shapley method by synthesizing risk, enterprise distribution service quality, time to join the union, and core competitiveness. Then he set the weights of the above factors by APH method. Peng et al. [23] introduced the contribution parameter to modify the Shapley value method and distributed more profits to the member enterprises whose contribution rates were higher than the average 
contribution rate. The value of the contribution rate was given by the scoring team composed of managers dispatched by each member enterprise. Qu [24] used the Shapley value method to solve the profit distribution model of third-party logistics joint distribution, and emphasized that the application of the Shapley value method not only reflected the rationality of the joint distribution participants, but also ensured an incentive and fairness. Runhong Zhang and Luo [25] considered the personalized service cost borne by enterprises in the distribution process so as to revise the Shapley value method. Yang [26] considered the existing risks of the cooperative alliance, namely, the success rate of cooperation, and introduced cooperation risk factors in order to improve the Shapley value method to solve the problem of rising transaction costs caused by cooperation risks in the process of cooperation. $\mathrm{Mu}$ [27] suggested that the risks faced by the joint distribution alliance in the specific operation process should be divided through quantitative and qualitative analysis, and the risks borne by each member enterprise in the joint operation should be fully considered so as to make a profit distribution more fair and reasonable through risk compensation. Yang [28] took the input resource factor as the consideration factor of output profit distribution and optimized the original calculation model. Xu et al. [29] constructed a comprehensive correction model of the Shapley value for the joint distribution model of transit stations, and combined it with the influence of customer delivery order caused by the shared distribution of transit stations on customer satisfaction, taking the delivery time, namely, the time cost paid by each express delivery enterprise, as one of the bases for profit distribution. $\mathrm{Li}$ [30] considered the risk cost, brand trust, and alliance loyalty, and used the comprehensive correction factor to establish the profit distribution model of dynamic logistics alliance based on the improved Shapley value method. Sun and Zhang [31] introduced the three factors affecting the profit distribution of the enterprise: comprehensive strength, the investment amount, and the amount of risk taking to build the improved Shapley model of the profit distribution of the alliance of small and medium-sized logistics enterprises under the platform business model.

The above scholars only considered one realistic factor when revising the traditional Shapley value method, but the realistic factors influencing the profit distribution scheme are often diverse and correlated with each other. In view of this, this paper introduces a comprehensive adjustment factor when revising the Shapley value method to consider three realistic factors in the allocation method at the same time, and we analyzed the correlations between factors and their influences on the allocation scheme.

\section{Model Construction}

\subsection{Sharing Mode of the Express Industry}

With the idea of cloud warehouse mode and joint distribution mode, combined with the characteristics of scattered distribution and seasonal blow-up of the express delivery industry, this paper believes that unified warehouse and distribution mode is very suitable for the express industry sharing mode. This mode, starting from storage and distribution, directly captures the key to the operation of the express industry. In the aspect of warehousing and distribution, the information, personnel, and resources sharing and the overall arrangement of the alliance should be satisfied. In other words, express enterprises should realize the sharing of warehouses, personnel, information, and resources, coordinate and arrange together, and reasonably select and arrange the warehouse according to the actual situation of the distribution area and each warehouse. This paper establishes a flowchart of the model of unified warehouse and distribution in the express industry, as shown in Figure 2. 


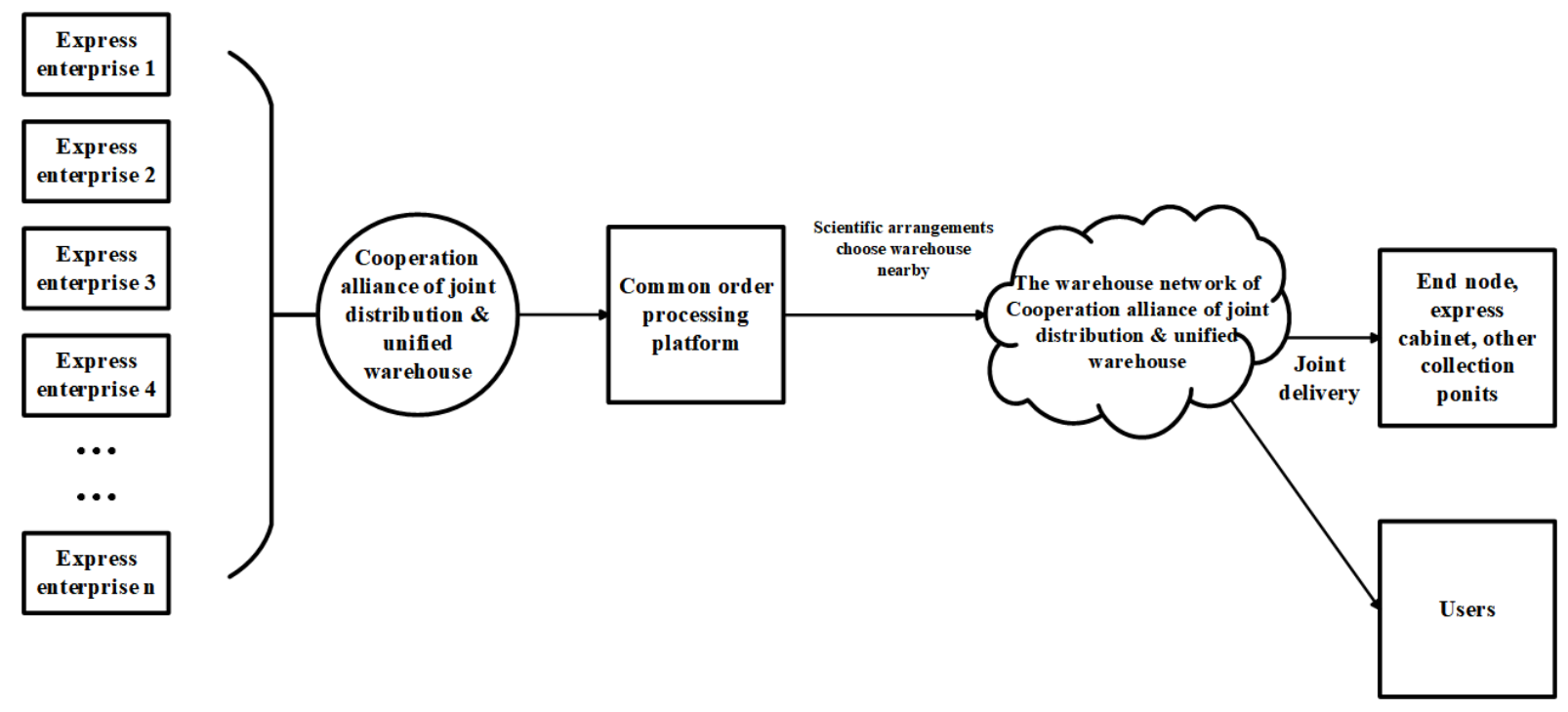

Figure 2. The flowchart of the model of a unified warehouse and distribution.

\subsection{The Improved Shapley Value Method}

Based on the actual situation and the research of scholars, this paper selects three factors that have an influence on the income of the express enterprise alliance, namely, the input capital contribution, risk contribution, and innovation research contribution.

The input capital contribution is used to measure the contribution of member enterprises to the whole alliance in transportation means, moving and unloading equipment, construction cost and site cost of the distribution center, human capital, financing cost, and other aspects.

Risk contribution is used to describe the proportion of risks taken by each member enterprise in the alliance. This kind of risk combines a variety of factors, including the market environment, industry competition environment, and the enterprise's situation. The alliance should evaluate the risks taken by each member enterprise and give certain income incentives to the high-risk member enterprises. For example, the earlier the member enterprises join the alliance, the greater the cooperation risk will be. Compared with the enterprises that enter the alliance when the alliance is of high yield and low risk, the member enterprises that join the alliance early deserve to receive more profits in the profit distribution.

The innovation research contribution is used to measure the contribution of member enterprises in the innovation research and development work of the alliance. The concept of innovative research contribution was put forward mainly because innovation is of great significance to the development of the future mode of the alliance, but the investment in innovation and research is large, and it is not easy to see the results in the short term. In order not to discourage the enthusiasm of member enterprises in the field of innovation and research, the alliance should give appropriate encouragement to the member enterprises that make contributions in this part, even if the profits gained from cooperation cannot directly reflect the efforts of member enterprises in this part.

Thus the thought block diagram can be obtained, shown in Figure 3. 


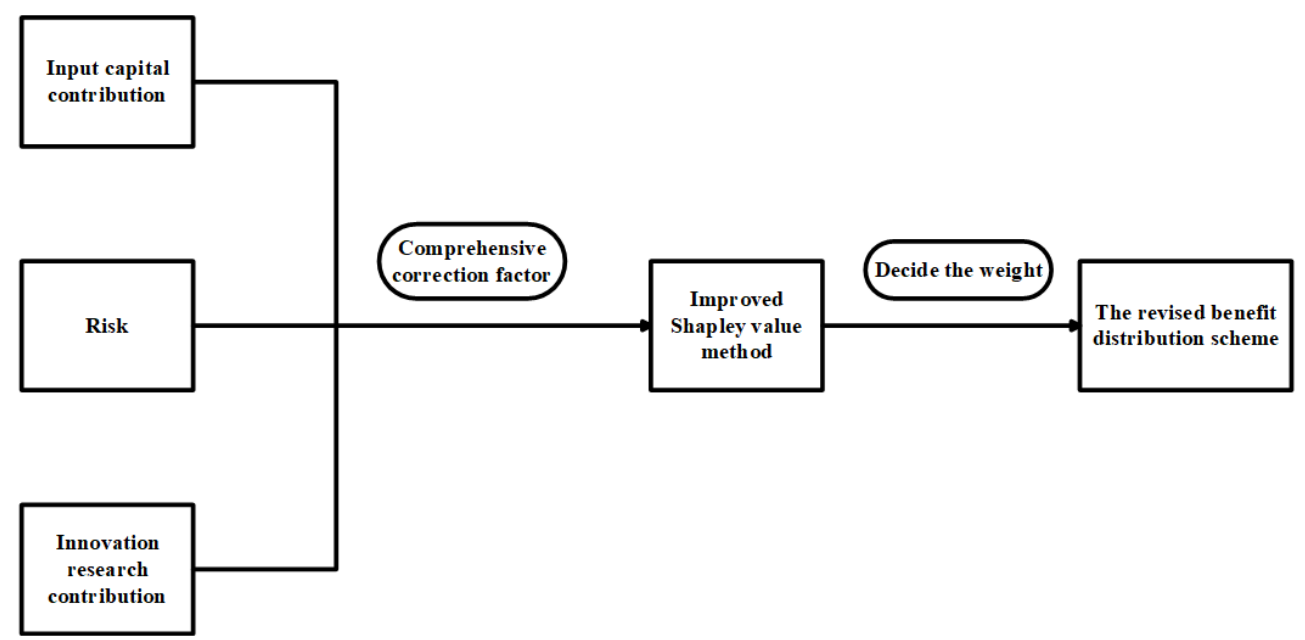

Figure 3. The thought block diagram of the improved Shapley value method.

The revised profit distribution scheme is:

$$
\begin{gathered}
\varphi_{i}^{\prime}=\varphi_{i}+\Delta \lambda_{i} \times v(s) \\
\Delta \lambda_{i}=\lambda_{i}-\frac{1}{n} \\
\lambda_{1}=\sum_{\mathrm{k}=1}^{m} \delta_{k} \times x_{i}^{(k)}
\end{gathered}
$$

Among them, the weights of these three factors in Equation (5) can be obtained by AHP. $\varphi_{i}^{\prime}$ is member $i^{\prime}$ s share of the profits after amended. $\varphi_{i}$ is member $i$ 's share of the profits calculated by traditional Shapley value method. $\lambda_{i}$ is the comprehensive correction factor. $\mathcal{E}_{i}$ is the weight of three factors: investment capital, risk, and sharing of innovative research. $x_{i}^{(k)}$ is the value of member $i$ on the $k$ th factor. $m$ is the number of factors. $\Delta \lambda_{i}$ is the difference between the comprehensive evaluation and the average evaluation. As the contribution of members is calculated according to $\frac{1}{n}, \Delta \lambda_{i}$ reflects the deviation according to $\frac{1}{n}$. Thus below must be satisfied:

$$
\begin{gathered}
\sum_{i=1}^{n} \Delta \lambda_{i}=0 \\
\sum_{i=1}^{n} \lambda_{i}=1
\end{gathered}
$$

After considering the three factors simultaneously, this paper designs the correlation among the three factors through the causal diagram shown in Figure 4, and describes the risk as a factor jointly determined by the input capital contribution, innovative research contribution, and one other factor, and further revises the risk contribution as follows:

$$
\begin{gathered}
\vartheta_{i}=k_{1} f\left(\theta_{i}\right)+k_{2} g\left(\rho_{i}\right)+k_{3} \\
k_{1}+k_{2}+k_{3}=1
\end{gathered}
$$

Among them, $k_{i}$ is the weight constant, where $k_{3}$ is a constant value used to reflect the influence of other factors that influence the risk. The value of $k_{i}$ can be determined by further research and discussion between the alliances. In the equation, $f\left(\theta_{i}\right)$ represents the impact of the input capital contribution on the risk in the causal diagram, and $g\left(\rho_{i}\right)$ represents the impact of innovative research contributions on risk, while the influence of other factors is included in the $k_{3}$. 


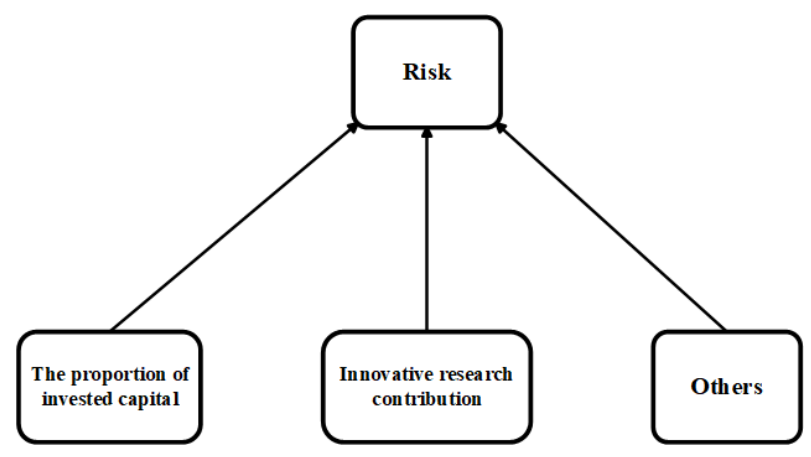

Figure 4. Three identified risk factors.

Through such a causal equation, we can clearly show the complex causal or association relationships that may exist among different factors. The relationship presented in this paper is flexible and can vary according to the number and types of factors considered in the model. In the following part of the experiment, we will give the predefined $f\left(\theta_{i}\right)$ and $g\left(\rho_{i}\right)$ functions and examine their impact on the final profit allocation.

Finally, this paper continues to modify the Shapley value method while considering the influences of the changing of factors on profit distribution. The purpose of the modification is to make the distribution scheme more reasonable and fair, to provide an incentive for the allied enterprises. For example, the proportions of the risks borne by a member enterprise rise from $10 \%$ to $30 \%$ and from $30 \%$ to $60 \%$. According to the traditional algorithm, the increase of the same magnitude brings the enterprise the same value of increment of profits. However, the actual situation is that the difficulty and determination of member enterprises to bear the increasing of the proportion of the risk under the condition of $10 \%$ and $30 \%$ of the risk are different. Therefore, for the latter situation, which is more complicated, it can only be realized by encouraging and distributing more profits. In this paper, the influence of factor change on the distribution result is reflected by changing the power number of factor terms. For example, Equation (10) changes the power number of risk contribution to two, and the updated comprehensive correction factor is:

$$
\lambda_{i}=\delta_{1} x_{i}^{(1)}+\delta_{2}\left[x_{i}^{(2)}\right]^{2}+\delta_{3} x_{i}^{(3)}
$$

Then we normalize all of the $\lambda_{i}$, so it ends up with

$$
\lambda_{1}^{\prime}=\lambda_{1}-\frac{\sum_{i=1}^{n} \lambda_{1}}{n}
$$

\section{Simulation Experiment}

The results of the correction method are verified by examples and experiments. The experiment proves that when the weights of different factors change, the improved Shapley value method can make the enterprises making more contributions to factors with higher weights get more profits.

Now assume that there are three express enterprises 1,2, and 3, and their operating expenses are CNY 170,000, CNY 250,000, and CNY 300,000 respectively. Their cooperation may be as follows:

1. Enterprises 1,2 carry out cooperation, and enterprise 3 carries out business alone. The total cost at this time is CNY 500,000.

2. Enterprises 1, 3 carry out cooperation, and enterprise 2 carries out business alone. The total cost at this time is CNY 520,000.

3. Enterprises 2, 3 carry out cooperation, and enterprise 1 carries out business alone The total cost at this time is CNY 450,000.

4. Enterprises 1, 2, 3 carry out cooperation The total cost at this time is CNY 320,000. 
According to the traditional Shapley value method, the following calculation can be carried out to obtain the distribution profits of enterprises 1,2, and 3 in the alliance in Tables 1-3.

Table 1. Profit distribution table of enterprise 1.

\begin{tabular}{ccccc}
\hline $\mathbf{( s )}$ & $\mathbf{( 1 )}$ & $\mathbf{( 1 , 2 )}$ & $\mathbf{( 1 , 3 )}$ & $\mathbf{( 1 , 2 , 3 )}$ \\
\hline$v(s)$ & 0 & 22 & 20 & 40 \\
$v(s-\{1\})$ & 0 & 0 & 0 & 27 \\
$v(s)-v(s-\{1\})$ & 0 & 22 & 20 & 13 \\
$|s|$ & 1 & 2 & 2 & 3 \\
$\omega(|s|)$ & $1 / 3$ & $1 / 6$ & $1 / 6$ & $1 / 3$ \\
$\omega(|s|)[v(s)-v(s-\{1\})]$ & 0 & 3.67 & 3.33 & 4.33 \\
\hline
\end{tabular}

Table 2. Profit distribution table of enterprise 2.

\begin{tabular}{ccccc}
\hline$(s)$ & $\mathbf{( 2 )}$ & $\mathbf{( 1 , 2 )}$ & $\mathbf{( 2 , 3 )}$ & $\mathbf{( 1 , 2 , 3 )}$ \\
\hline$v(s)$ & 0 & 22 & 27 & 40 \\
$v(s-\{2\})$ & 0 & 0 & 0 & 20 \\
$v(s)-v(s-\{2\})$ & 0 & 22 & 27 & 20 \\
$|s|$ & 1 & 2 & 2 & 3 \\
$\omega(|s|)$ & $1 / 3$ & $1 / 6$ & $1 / 6$ & $1 / 3$ \\
$\omega(|s|)[v(s)-v(s-\{2\})]$ & 0 & 3.67 & 4.5 & 6.67 \\
\hline
\end{tabular}

Table 3. Profit distribution table of enterprise 3.

\begin{tabular}{ccccc}
\hline $\mathbf{( s )}$ & $\mathbf{( 3 )}$ & $\mathbf{( 1 , 3 )}$ & $\mathbf{( 2 , 3 )}$ & $\mathbf{( 1 , 2 , 3 )}$ \\
\hline$v(s)$ & 0 & 20 & 27 & 40 \\
$v(s-\{3\})$ & 0 & 0 & 0 & 22 \\
$v(s)-v(s-\{3\})$ & 0 & 20 & 27 & 18 \\
$|s|$ & 1 & 2 & 2 & 3 \\
$\omega(|s|)$ & $1 / 3$ & $1 / 6$ & $1 / 6$ & $1 / 3$ \\
$\omega(|s|)[v(s)-v(s-\{3\})]$ & 0 & 3.33 & 4.5 & 6 \\
\hline
\end{tabular}

Therefore, according to the traditional Shapley value method, the profits of enterprises can be obtained as $\varphi_{1}=0+3.67+3.33+4.33=11.33$ (ten thousand CNY) $\varphi_{1}=0+3.67+$ $4.5+6.67=11.33$ (ten thousand CNY) $\varphi_{1}=0+3.67+4.5+6.67=11.33$ (ten thousand $\mathrm{CNY}$ ). Hence, we get three $\varphi_{i}$ in the correction algorithm. The following experiment shows the benefit distribution effect of the modified algorithm in the case of this example.

This paper assumes that $k_{1}=0.2, k_{2}=0.1, k_{3}=0.7$ and the values in Table 4 . The piecewise function of the investment fund contribution and innovation research contribution in Equation (8) is also given. The specific value of risk contribution is determined by Equation (8). When constructing functions $f\left(\theta_{i}\right)$ and $g\left(\rho_{i}\right)$, combined with practical considerations, the following expression can be obtained:

$$
\begin{gathered}
f\left(\theta_{i}\right)=\left\{\begin{array}{l}
\frac{3}{5} \theta_{i}, 0 \leq \theta_{i}<\frac{1}{3} \\
\frac{4}{5} \theta_{i}-\frac{1}{15}, \frac{1}{3} \leq \theta_{i}<\frac{1}{2} \\
\frac{4}{3} \theta_{i}-\frac{1}{3}, \frac{1}{2} \leq \theta_{i} \leq 1
\end{array}\right. \\
g\left(\rho_{i}\right)=\left\{\begin{array}{l}
\frac{1}{6}, 0 \leq \rho_{i}<\frac{1}{3} \\
\frac{5}{12}, \frac{1}{3} \leq \rho_{i}<\frac{1}{2} \\
\frac{7}{12}, \frac{1}{2} \leq \rho_{i}<\frac{2}{3} \\
1, \frac{2}{3} \leq \rho_{i} \leq 1
\end{array}\right.
\end{gathered}
$$


Table 4. Assumed $\theta_{i}$ and $\rho_{i}$ of three enterprises.

\begin{tabular}{cccc}
\hline & Enterprise 1 & Enterprise 2 & Enterprise 3 \\
\hline$\theta_{i}$ & 0.1 & 0.4 & 0.5 \\
$\rho_{i}$ & 0.5 & 0.4 & 0.1 \\
\hline
\end{tabular}

In the experiment, we fixed the above data (enterprise cost, $k_{i}, \theta_{i}$ and $\rho_{i}$ of three enterprises, $f\left(\theta_{i}\right)$ and $\left.g\left(\rho_{i}\right)\right)$. Then we modified the weights of different factors, and traversed all $\left(\delta_{1}, \delta_{2}, \delta_{3}\right)$ satisfying $\delta_{1}+\delta_{2}+\delta_{3}=1$. After that we combined and calculated the corresponding profit distribution results, as is shown in Figure 5.

In Figure 5, the change of the benefit distribution result (axis $z$ ) with the weight of each factor is plotted (axis $x$ refers to $\delta_{1}$, axis $y$ refers to $\delta_{2}$, accordingly; $\delta_{3}=1-\delta_{1}-\delta_{2}$ ). For every eligible $\left(\delta_{1}, \delta_{2}, \delta_{3}\right)$, the corresponding result of profit distribution can be directly drawn from the graph as a line perpendicular to plane $x y$ and its intersection point is $\left(\delta_{1}, \delta_{2}\right)$. The value $\varphi$ corresponding to the three intersection points of the plane in the figure is the final benefit distribution result $\varphi_{i}^{\prime}$. It can be seen from the figure that the correction algorithm conforms to our expectation. For example, we can find from the form of the blue curved surface that as $\delta_{1}$ increases, the shared interests of enterprise 1 is in decline, because the increase of $\delta_{1}$ represents that when allocating profits, the alliance focuses on distributing more benefits to the enterprises that contribute more capital. Among the three enterprises, the investment capital contribution of enterprise 1 only accounts for $10 \%$ of the whole alliance, so as the alliance pays more attention to the input capital contributions, the benefits of enterprise 1 will decrease.

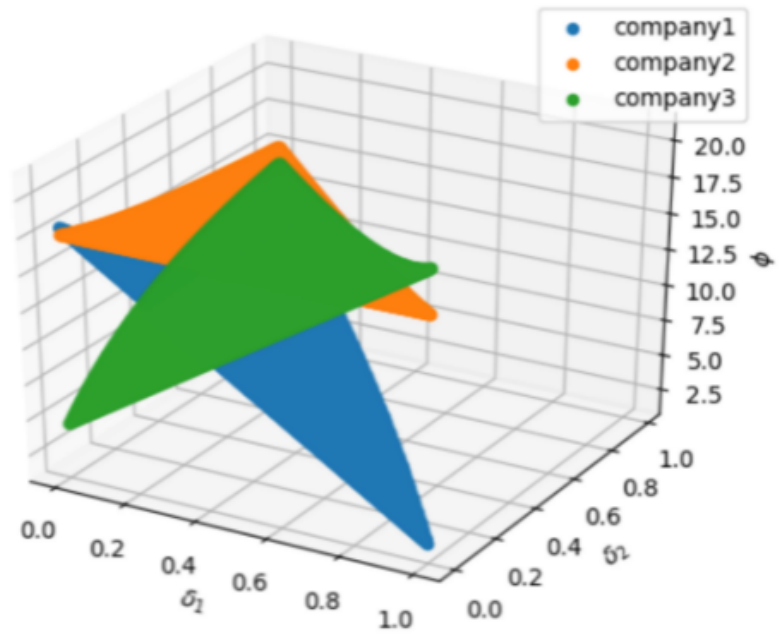

Figure 5. The variation of the result of profit distribution with the weight of each factor.

In the previous chapter, the weight of each factor was obtained by comparing the given importance matrix with AHP. Since the expert score cannot be obtained, this experiment traverses the possible weight space to study the influences of different weights on the final benefit distribution. As the results in this experiment contain all weighing possibilities, that is, the ratings given by possible experts, they are more general and broader.

In addition, in order to more intuitively reflect the relationship between the results of benefit distribution and different variables, we drew three groups of experimental results, as shown in Figures 6-8, respectively, showing the changes of the results of benefit distribution with a certain factor. 


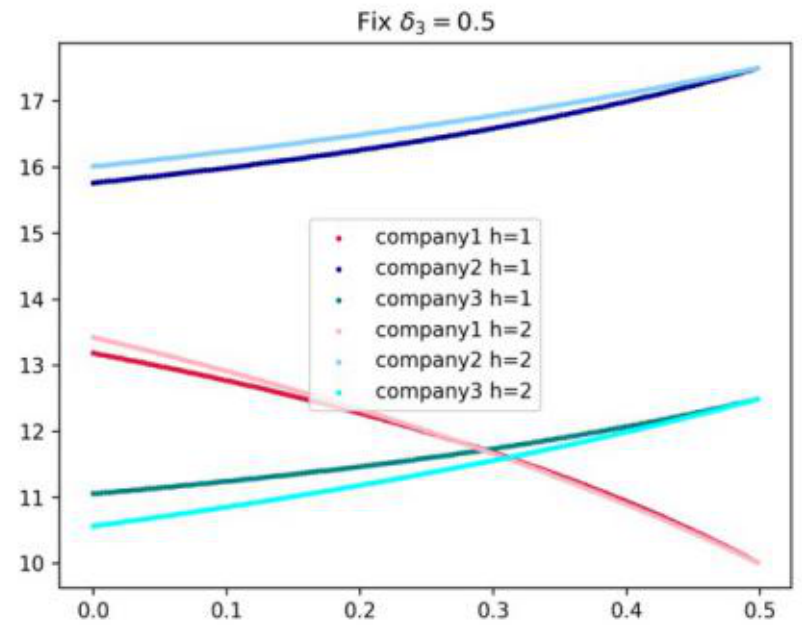

Figure 6. The result of the distribution of profits varies with $\delta_{1}\left(\delta_{3}\right.$ is fixed).

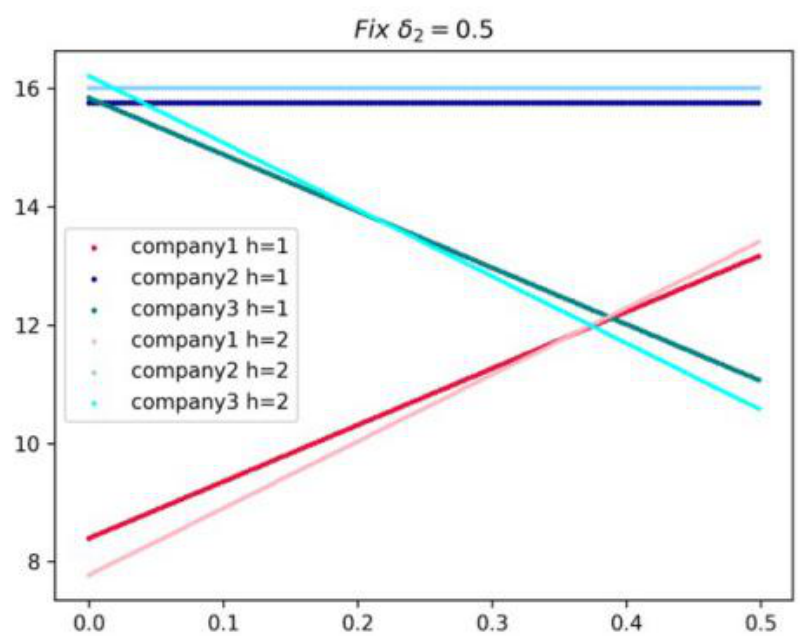

Figure 7. The result of the distribution of profits varies with $\delta_{3}\left(\delta_{2}\right.$ is fixed).

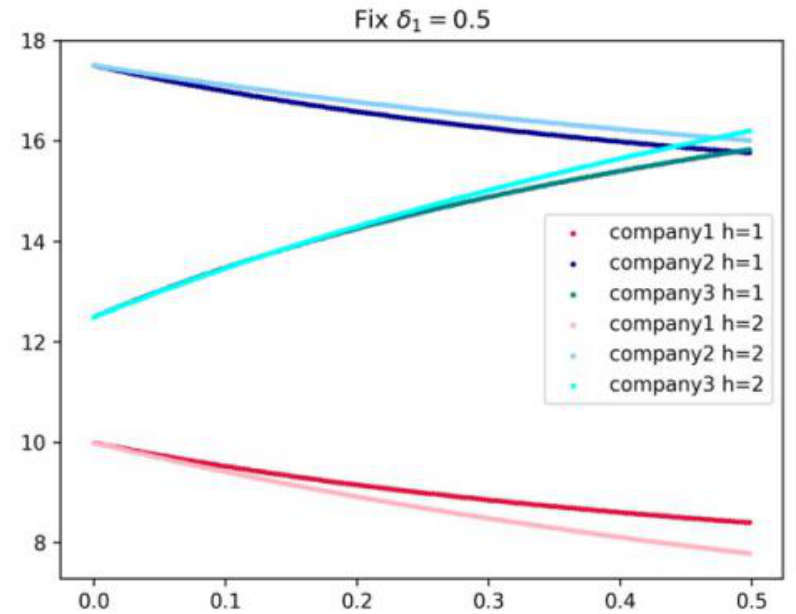

Figure 8. The result of the distribution of profits varies with $\delta_{2}\left(\delta_{1}\right.$ is fixed).

Among them, the horizontal axis represents the weight of change and the vertical axis represents the result of profit distribution. In each figure, the weight of one factor was fixed at 0.5 to change other weights, and the final profit distribution results were compared under the conditions of power being one and power being two. However, this experiment has given the specific values of three factors of three enterprises, so the experiment fails to reflect the influence of the power in the algorithm. 


$$
\begin{aligned}
& \varphi_{2}^{\prime}=\varphi_{2}+\Delta \lambda_{2} \times v(s) \\
& =\varphi_{2}+\left(\delta_{1} \theta_{2}+\delta_{2} \vartheta_{2}^{h}+\delta_{3} \rho_{2}-\frac{1}{N}\right) \times v(s)
\end{aligned}
$$

Take Figure 7 for example. It can be seen that when $\delta_{2}=0.5$ is fixed, the profits of enterprise 2 remain unchanged along with the change of $\delta_{3}$. This is due to the numerical particularity of the examples used in this experiment, since Equation (14) is used to calculate the interests of enterprise 2 when the power is 1 and the power is 2 (where $N$ is the number of participating enterprises and the value is 3). Besides, the weight of risk $\delta_{2}$ is fixed. As the weight of innovation research contribution factor $\delta_{3}$ changes, the weight of capital investment factor $\delta_{1}=0.5-\delta_{3}$ also changes. However, in enterprise 2 in the example $\theta_{2}=\rho_{2}=0.4$, the change of $\delta_{3}$ does not affect the interests of enterprise 2 under the condition of fixing $\delta_{2}$. In addition, it can be seen that, with the increase of $\delta_{3}$, shared interests of enterprise 1 become bigger and bigger. This is consistent with our expectations, because enterprise 1 has the largest contribution to the enterprise's innovation study of the three companies, accounting for $50 \%$, so when assigning greater weights to innovative research contributions, namely, the innovation research contribution to measure supply chain member alliance, there seemed to be no more important contributions; members whose contributions in innovation research are greater will share more profits. It can be seen that the modified algorithm conforms to the expected effect.

However, the experiment in this paper has some shortcomings. That is, it fails to test the influence of power's change on the result of profit distribution. The experiment proves that the modified algorithm can consider the influences of three factors on the profit distribution at the same time, and adjust the result of the profit distribution according to the different weights of the factors to realize the fairness and rationality of the profit distribution.

\section{Conclusions}

Firstly, based on other modes and practices of shared logistics, we put forward some explanations of the connotations of shared logistics. Then we designed the operation mode of shared logistics based on the understanding of the connotations of shared logistics and the theory of other shared logistics modes in warehousing and distribution, and used the flow chart to reflect it. The member enterprises in the alliance share machines and manpower, and more importantly, form a warehouse network within the alliance, share information, and manage together to realize the whole operation of the alliance.

Secondly, it is difficult for independent enterprises in the express delivery industry to cooperate, and the cooperation mechanism lacks effective incentives, which is less attractive to express delivery enterprises. Besides, there are inevitable interest disputes when enterprises reach an alliance, which will affect the long-term cooperation of the alliance. In order to make the system's warehouse distribution patterns more likely come into practice, and in order to promote express enterprises' transformation from separate operations to cooperative operations by encouraging express enterprises to participate in the system storehouse of distribution alliance, this article emphatically discusses the alliance of interests distribution, and fixes the Shapley value method used for the evaluation of the contributions of members of the enterprise in the allocation process, making it more practically significant. While adhering to the idea of the Shapley value method being used to distribute benefits according to contributions, this paper has modified its unique calculation method in three aspects. Through an example, we used the traditional Shapley value method to calculate and change the weights according to the correction algorithm proposed in this paper. Then we used the matplotlib library for displaying all positions with the interests of the three members of the alliance distribution-results varied with the weights of different factors (namely, $\delta_{i}$ ) by 3D image, and we used the 2D images to compare the effects of the linear and nonlinear allocation methods (the power was 1 or 2 ), which are in line with the expectations of a correction algorithm. 
On the design of the mode of unified warehouse and distribution, due to the lack of practical investigations and enough internal data and cases, there may be assumptions that do not fit the reality. At present, for China's express enterprises, warehousing and distribution are the two key links and the main sources of high cost. Further combinations of research results and practical experience from other shared logistics modes at home and abroad will also be conducive to the further improvement and development of the mode of warehouse distribution, so as to promote the cooperation of express delivery enterprises, and help the express delivery industry to reduce costs and increase efficiency, and reform and innovate.

The improvement of the benefit distribution problem is based on the Shapley value method, so it fails to avoid the inherent use of many runs of the Shapley value method. However, by adding a comprehensive correction factor, using linear and nonlinear calculation methods, and considering the correlations between factors, the revised benefit distribution scheme is more practical and has more incentive significance. In the future, further in-depth study is needed, and other algorithms such as Raiffa are likely to be used to further improve the solution.

Author Contributions: Conceptualization, L.W.; methodology, writing—original draft, X.W.; writingreview and editing, X.C. All authors have read and agreed to the published version of the manuscript.

Funding: This research was funded by the National Key Research and Development Program of China grant number 2018YFB1403101.

Institutional Review Board Statement: Not applicable.

Informed Consent Statement: Not applicable.

Conflicts of Interest: The authors declare no conflict of interest.

\section{References}

1. Wang, L. Research on Joint Distribution Model and Location Selection in the Sharing Economy; University of International Business and Economics: Beijing, China, 2017.

2. Sarkar, B.; Saren, S. Ordering and transfer policy and variable deterioration for a warehouse model. Hacet. J. Math. Stat. 2017, 46, 985-1014. [CrossRef]

3. Shin, D.M.; Guchhait, R.; Sarkar, B.; Mittal, M. Controllable lead time, service level constraint, and transportation discounts in a continuous review inventory model. Rairo Oper. Res. 2016, 50, 924-934. [CrossRef]

4. Kumar Sett, B.; Sarkar, B.; Goswami, A. A two-warehouse inventory model with increasing demand and time varying deterioration. Sci. Iran. 2012, 19, 1969-1977. [CrossRef]

5. Li, J.; Wang, W.; Sun, X.; Wang, B.; Wang, M. Sharing mechanism construction and pattern analysis of shared warehouse and distribution system. Commod. Qual. 2018, 35, 166-172.

6. Yang, M.; Zhou, X. Construction of collaborative distribution pattern at the terminal of express under the background of "Internet Plus". J. Beijing Univ. Posts Telecommun. Soc. Sci. Ed. 2015, 17, 45-50.

7. Li, C. Analysis on the co-mode and operation mechanism of urban community logistics service. Commer. Age 2013, 10, 45-46.

8. $\mathrm{Wu}, \mathrm{G}$. Construction of a new mode of joint distribution alliance at the end of e-commerce logistics. Bus. Econ. Res. 2018, 20, 90-92.

9. Shi, Z. Foreign joint distribution system construction practice and experience for reference. Shanxi Sci. Technol. 2019, 34, 76-79.

10. Li, N. The theory and practice of logistics mutualization in Japan. Chin. Circ. Econ. 2019, 33, $27-39$.

11. Li, N. Analysis on the evolution and development mode of logistics colocalization in Japan. Mod. Jpn. Econ. 2015, 4, 77-86.

12. Ge, R. Research on the construction of urban common distribution system based on resource sharing. North. Econ. Trade 2017, 2, 62-63.

13. Li, M.; Zhang, H.; Wang, Y. Research review of urban joint distribution model and income distribution. Bus. Econ. Res. 2017, 8, 73-75.

14. Zhao, T. Research on Profit Distribution Mechanism of Rural Chain Supermarket Joint Distribution; Southwest Jiaotong University: Chengdu, China, 2016.

15. Shi, S. Research on the Formation and Operation Mechanism of Knowledge Alliance; Nankai University Press: Tianjin, China, 2015.

16. Li, L. Study on the Influencing Factors and Methods of Benefit Distribution of Chain Retail Joint Distribution Alliance; Hebei University of Technology: Tianjin, China, 2015.

17. Zhang, Y.; Chen, L.; Yuan, Y.; Mao, H.; Peng, F. Study on the profit distribution mechanism between intelligent logistics park and settled enterprises based on dynamic Bayes. Pract. Underst. Math. 2020, 50, 299-307.

18. Xu, S.; Li, N.; Ruan, Y.; Jiao, L.; Wang, C.; Ding, X. Profit distribution model of agricultural products based on improved shapley value of cloud logistics. Knowl. Trib. 2018, 25, 59. 
19. Zhang, X. Study on profit distribution of small and medium-sized logistics enterprises in agricultural products logistics organization cooperation. Logist. Technol. 2020, 43, 12-16.

20. Shapley, L.S. A Value for n-Person Games. Ann. Math. Stud. 1953, 28, 307-318.

21. Cai, R.; Hu, D. Research on the construction and profit distribution of express terminal service alliance based on cooperative game. Logist. Technol. 2019, 42, 9-14.

22. $\mathrm{Li}, \mathrm{H}$. Research on profit distribution of end joint distribution alliance of express delivery enterprises: Based on the improved Shapley value method. J. Zhengzhou Inst. Aviat. Ind. Manag. 2016, 34, 71-77.

23. Peng, M.; Zou, L.; Wei, X. A preliminary study on profit distribution based on joint distribution model. Chin. Mark. 2016, 49, 21-22.

24. Qu, J. Research on profit distribution model of third-party logistics joint distribution based on the Shapley value method. Guide Sci. Educ. Electron. Ed. Mid 2015, 1, 136-137.

25. Zhang, R.; Luo, R. Research on Benefit Assignment of Common Delivery Based on Shapley Value Method. J. Wuhan Univ. Technol. 2008, 30, 150-153.

26. Yang, D. Research on Distribution Center Selection and Profit Distribution under Joint Distribution; Dalian Maritime University: Dalian, China, 2005.

27. $\mathrm{Mu}, \mathrm{L}$. Analysis of Revenue Allocation Model for Joint Distribution Operation of Circulation Enterprises Based on Shapley Value Method. Tech. Methods 2014, 3, 212-215.

28. Yang, L. Application of Shapley Value Modified Model to Benefit Distribution of Supply Chain Alliance in Cross-border E-commerce Environment. Logist. Eng. Manag. 2018, 40, 105-107.

29. Xu, M.; Zhou, X.; Cui, L.; Liu, Y.; Yu, G. Low distribution density regional express joint distribution mode and profit distribution. Comput. Integr. Manuf. Syst. 2020, 26, 181-190.

30. Li, T. Benefit Distribution of Dynamic Logistics Alliance Based on Improved Shapley Value Method. Logist. Technol. 2020, 39, 106-110.

31. Sun, P.; Zhang, B. Research on profit distribution of small and medium-sized logistics enterprise alliance based on Shapley value modification under platform business mode. Bus. Res. 2019, 26, 123-128. 